\title{
O Princípio Constitucional da InTEgralidade de Assistência À Saúde e o Projeto de Lei n. 219/2007: INTERPRETAÇão e APLiCABILIDAde PELo Poder Judiciário
}

\author{
THE CONSTITUTIONAL PRINCIPLE OF THE INTEGRALITY OF HEALTH \\ ASSISTANCE AND THE LAW PROJECT N. 219/2007: INTERPRETATION \\ AND APPLICABILITY BY THE JUDICIARY POWER
}

Silvia Badim Marques(*)

\section{RESUMO}

Este artigo pretende analisar o Projeto de Lei n. 219 de 2007, do Senado Federal, de autoria do senador Tião Viana (PT/AC), que propõe a alteração do art. $6^{\circ}$ da Lei n. 8.080, de 19 de setembro de 1990, para definir o conceito de integralidade de assistência à saúde, reduzindo-o à oferta dos procedimentos e medicamentos constantes na política pública de saúde. Pretende, também, analisar: a) a construção histórica do direito à saúde no Brasil; b) a aplicação do princípio constitucional de integralidade de assistência à saúde pelo Poder Judiciário e; c) o conflito que se trava hoje entre juízes e gestores públicos de saúde; e d) discutir as implicações de uma definição restritiva de tal princípio por uma lei emanada do parlamento, que pretende solucionar o conflito ora exposto.

\section{Palavras-chave}

Assistência à Saúde; Cidadania; Direito à Saúde; Poder Judiciário

(*) Mestre e doutoranda em Direito pela Faculdade de Saúde Pública da Universidade de São Paulo, pesquisadora colaboradora do Programa de Direito Sanitário da FIOCRUZ - Brasília. E-mail: <sbadim@fiocruz.br>. Recebido em 29.01.09. Aprovado em 19.02.09. 


\begin{abstract}
This article intends to analyze the 2007 Law Project $n .219$, from Federal Senate, whose authorship is Senator Tião Viana (PT/AC). This project intends to change the article $6^{\text {th }}$. of the Brazilian Law n. 8.080 (September 19, 1990 ) in order to define the concept of integrality of the health assistance, by reducing it to the offering of procedures and medicines included in the public politics of health. This work also intends to analyze: a) the historical construction of the right to health in Brazil; b) the application of the constitutional principle of integrality of health assistance by the Judiciary Power and (c) the conflict that exists today between judges and public managers of health and d) to discuss the implications of a restrictive definition of such principle for a law originated in the Parlament that intends to solve the mentioned conflict.
\end{abstract}

\title{
Keywords
}

Citizenship; Health Assistence; Judicial Power; Right to Health

\section{INTRODUÇÃO}

A saúde foi reconhecida como um direito integral e universal de todos os cidadãos brasileiros na Constituição Federal de 1988. Pretende-se, no presente artigo, reconstruir historicamente a positivação deste direito no ordenamento jurídico brasileiro, a fim de que a experiência do passado possa, com sorte, trazer ensinamentos que nos permitam refletir acerca das atuais proposições legislativas concernentes à temática. $\mathrm{E}$, também, refletir sobre a importância deste direito fundamental ser concebido sobre a perspectiva universal e integral, capaz de salvaguardar o cuidado digno com a saúde de cada cidadão brasileiro, com respeito as suas diversidades e particularidades.

Por experiência do passado, neste artigo, entendem-se os fatos ocorridos nas décadas que antecederam à Constituição Federal de 1988, relacionados à proteção sanitária prestada pelo Estado e sua inserção como um direito de cidadania no país. O breve relato histórico que se segue será trazido na perspectiva de Foucault que, segundo Veyne ${ }^{(1)}$, é o primeiro historiador verdadeiramente positivista, no sentido de desconectar a história de interpretações conduzidas pela ideologia ou por conceitos preconcebidos. Assim, os fatos humanos serão tomados como raridades, não como instalados na plenitude da razão. Ele destaca que "há um vazio em torno deles para outros fatos que nosso saber nem imagina"(2). Ou seja, os fatos humanos são

(1) VEYNE, Paul. Como se escreve a história. 4. ed. Brasília: Ed. da UnB, 1988.

(2) Id. Ibid., p. 240. 
arbitrários, mas não são óbvios; "no entanto parecem tão evidentes aos olhos dos contemporâneos e mesmo de seus historiadores que nem uns nem outros sequer os percebem"(3). Salienta o autor ${ }^{(4)}$ também que:

julgar as pessoas por seus atos não é julgá-las por suas ideologias; é, também, não as julgar a partir de grandes noções eternas - os governados, o Estado, a liberdade, a essência da política - que banalizam e tomam anacrônica a originalidade das práticas sucessivas.

Sem a pretensão de esgotar a temática ou de revelar alguma verdade por meio das ocorrências históricas, pretende-se apenas trazer à tona os fatos relativos à consolidação jurídica do direito à saúde no país e ao papel do cidadão brasileiro em relação ao exercício deste direito. Isto para que possamos introduzir a discussão relacionada à garantia de princípios constitucionais amplos como o da universalidade e integralidade de assistência e situarmos essa discussão na problemática que hoje se trava entre os gestores públicos e o Poder Judiciário, relacionada à legitimidade deste Poder para garantir integralmente o direito em cada caso concreto submetido a sua apreciação. E discutir em que medida a aplicação destes princípios constitucionais pelo Poder Judiciário significa uma afronta à política estabelecida e aos serviços prestados discricionariamente pelos órgãos sanitários competentes.

Por fim, pretende-se analisar o projeto de lei que hoje tramita no Senado Federal de n. 219 de 2007 que, ao reduzir o conceito de integralidade de assistência às políticas públicas estabelecidas em matéria de assistência farmacêutica e terapêutica, tem a pretensão de minimizar ou solucionar o conflito relacionado à aplicabilidade deste princípio pelo Poder Judiciário e, por conseguinte, resolver o problema do lobby da indústria farmacêutica que pretende (indevidamente, de acordo com as justificativas do projeto de lei), a compra de quaisquer medicamentos pelo Sistema Único de Saúde - SUS, mediante a intervenção do Poder Judiciário.

\section{A POSITIVAÇÃO DO DIREITO À SAÚDE NO BRASIL}

As Constituições anteriores a de 1988 não tratavam a saúde como um direito. Uma breve abordagem das Constituições republicanas nos permite constatar que a incorporação e construção dos direitos sociais, em especial do direito à saúde, se deram de forma vagarosa no Brasil(5). O sistema público de saúde brasileiro, até a promulgação da Constituição Federal de 1988, não merecia um tratamento constitucional específico e atendia somente aos

(3) VEYNE, Paul. op. cit., p. 240.

(4) Id. Ibid., p. 248.

(5) DALLARI, Sueli Gandolfi. Os Estados brasileiros e o direito à saúde. São Paulo: Hucitec, 1995. 
indivíduos que contribuíssem à Previdência Social, ou seja, aqueles indivíduos que possuíssem carteira de trabalho assinada.(6)

Conforme salienta $\operatorname{Cohn}^{(7)}$, o atendimento à saúde da população excluída do mercado formal de trabalho não configurava um direito dos cidadãos, não constituía uma obrigação do Estado, decorrente de exigência constitucional. Os indivíduos que não contribuíssem para a previdência social ou eram atendidos pelas Santas Casas de Misericórdia, a título de benevolência ou, se possuíssem recursos financeiros, recorriam a serviços médicos privados. Destaca a autora ${ }^{(8)}$ que "o marco comum é a concepção do direito como um privilégio vinculado à contribuição previdenciária e/ou de seguros privados". Ou, nas palavras de $\operatorname{Santos}^{(9)}$, ao analisar a política socioeconômica do pós-30 no Brasil, o direito à saúde e a previdência social configuram uma cidadania regulada, onde reconhecem-se como cidadãos somente aqueles que apresentam uma das ocupações reconhecidas e definidas por lei. Conh e Elias $^{(10)}$ asseveram ainda que tais prestações e benefícios constituíram-se menos (ou quase nada) como função de sua "condição de cidadão ou trabaIhador, e sim do reconhecimento da sua situação ocupacional oficialmente legitimada e vinculada a uma obrigação contratual de caráter contributivo".

Salienta-se que o papel do Estado, em relação à prestação em matéria de saúde, como um direito do trabalhador assalariado, resumia-se à prestação de assistência médica e restringia-se basicamente ao gerenciamento da compra e oferta dos serviços privados de saúde aos beneficiários públicos. Lógica esta presente desde a criação do chamado Instituto Nacional da Previdência Social - INPS, em 1966, que inseriu a prestação sanitária dentre as ofertas públicas decorrentes da contribuição previdenciária.

O Ministério da Saúde desde sua criação, em 1953, prestou assistência médica aos desafortunados e excluídos do mercado de trabalho, mas, de forma limitada e insuficiente em relação à demanda por cuidados de saúde ${ }^{(11)}$.

(6) Merece destaque apenas a Constituição promulgada em 1934 que chegou a esboçar um cuidado mais abrangente com a saúde e com os direitos dos trabalhadores, conferindo competência concorrente à União e aos Estados para cuidar da saúde e medidas sanitárias a serem adotadas pelas três esferas de governo. Esse cuidado mais amplo por todos os entes federativos será retomado apenas na Constituição de 1988. DALLARI, Sueli Gandolfi. op. cit.

(7) CONH, Amélia et al. A saúde como direito e como serviço. 3. ed. São Paulo: Cortez; 2002.

(8) Id. Ibid., p. 21.

(9) SANTOS, Wanderley Guilherme. Cidadania e justiça: a política social na ordem brasileira. Rio de Janeiro: Campus, 1979.

(10) COHN, Amélia; ELIAS, Paulo. Saúde no Brasil: políticas e organização de serviços. 5. ed. São Paulo: Cortez, 2003. p. 18.

(11) De acordo com CONASS (Conselho Nacional dos Secretários de Saúde. Sistema Único de Saúde. Para entender a gestão do SUS. Brasília: CONASS, 2007. Coleção PROGESTORES. Livro 1), a atuação do Ministério da Saúde (MS) e das Secretarias de Saúde dos Estados e municípios na prestação de assistência à saúde era bastante limitada, restringindo-se às ações desenvolvidas por alguns poucos hospitais próprios e pela Fundação de Serviços Especiais de Saúde Pública (FSESP) e dirigidas à população não previdenciária — os chamados indigentes. Estes indigentes tinham ainda, por uma atividade caritativa, acesso a serviços assistenciais de saúde prestados por instituições de caráter filantrópico como as chamadas Santas Casas. 
Essas prestações, todavia, não configuravam direito dos cidadãos e sim uma mera liberalidade do Estado, uma obrigação moral para com os que padeciam e necessitavam de amparo, sem coerção jurídica.

Em 1974, cria-se o Ministério da Previdência e Assistência Social, no qual se inclui a prestação de assistência médica aos contribuintes, em 1977. Este Ministério se divide então em dois Institutos: o Instituto da Previdência Social (INPS) e Instituto Nacional de Assistência Médica da Previdência Social (INAMPS). Este se configurava em uma rede credenciada e conveniada de prestadores privados de assistência médica, gerenciada pelo Estado, e responsável pela oferta pública de assistência médica aos cidadãos-contribuintes.

Fica patente a divisão dos cuidados com a saúde, entre os Ministérios da Previdência Social e da Saúde. Uma lógica fragmentada que dividia os cidadãos entre assalariados e não assalariados, que condicionava o acesso a determinados serviços à condição de contribuinte da previdência social e deixava o resto da população não contribuinte à oferta benevolente de cuidados com a saúde, nas filas das Santas Casas de Misericórdia. No plano jurídico, não havia proteção legal capaz de garantir o acesso dessa população aos serviços de saúde, equiparando-a população contribuinte. Não havia a garantia do direito à saúde, como um direito integral e universal de todos os cidadãos brasileiros.

Percebe-se, desta forma, que no Brasil a proteção jurídica à saúde de todos, independentemente de quaisquer requisitos como renda e inserção no mercado de trabalho, era inexistente. Os cidadãos não tinham direito de receber qualquer assistência médica ou sanitária do Estado, a menos que preenchessem os requisitos necessários (contribuintes da previdência social).

Essa situação culminou numa enorme crise na área da saúde, permeada pela noção de injustiça social, onde filas de pessoas aguardavam um atendimento médico benevolente, capaz de, muitas vezes, salvar vidas ${ }^{(12)}$. Denúncias eram frequentes em jornais e revistas, e o desamparo no atendimento aos cidadãos era um fato que apenas podia ser lastimado moralmente, sem possibilidade de intervenção jurídica.

\section{A conjuntura internacional de proteção à saúde}

No plano internacional, principalmente depois da Segunda Guerra Mundial, os denominados direitos humanos (direitos que compõem a dignidade humana, indispensáveis a qualquer ser humano) adquirem relevância internacional, também fundada na relação estreita que vem a ser instituída

(12) COHN, Amélia; ELIAS, Paulo. op. cit. 
entre direitos humanos e democracia. $\mathrm{E}$, dentre esses direitos, considerados inerentes à pessoa humana, encontra-se o direito à saúde ${ }^{(13)}$.

A afirmação da saúde como um direito ganha relevância principalmente com a Declaração Universal dos Direitos Humanos de 1948, que introduz os elementos que passariam a caracterizar os direitos humanos: universalidade, interdependência e indivisibilidade. A Declaração Universal afirma, em seu art. 25, que: "toda pessoa tem direito a um nível de vida adequado que the assegure, assim como à sua família, a saúde (...)". A saúde também é reconhecida como direito no Pacto Internacional de Direitos Econômicos, Sociais e Culturais de 1966, em seu art. 12-1, que afirma o reconhecimento "do direito de toda pessoa ao desfruto do mais alto nível possível de saúde física e mental". Destaca-se que este Pacto somente foi ratificado pelo Brasil em 1992, data em que já era vigente a Constituição Federal de 1988.

Nesses documentos, o direito à saúde é abordado de forma abrangente, como destacam Dallari e Fortes ${ }^{(14)}$ :

desde a típica face individual do direito subjetivo à assistência médica em caso de doença, até a constatação da necessidade do direito do Estado ao desenvolvimento, personificada no direito a um nível de vida adequado à manutenção da dignidade humana. Isso sem esquecer o direito à igualdade implícito nas ações de saúde.

A Declaração de 1948, de acordo com Marramao(15), contém em si um elemento dinâmico que encontra a sua expressão mais incisiva no art. 28 , o qual dispõe que: "Todo indivíduo tem direito a uma ordem social e internacional na qual os direitos e as liberdades enunciados nesta Declaração possam ser plenamente realizados". A implementação desses direitos, portanto, finca-se sobre uma projeção em direção a uma dinâmica de realização histórica. Os princípios contidos no texto e os desafios de sua garantia efetiva não são colocados simplesmente como problema, mas sim, enunciados como direitos. Assim, os rumos históricos são previamente definidos como direitos pela Declaração, no sentido da garantia nacional de cada um deles, em cada país, rumo a uma ordem efetivamente democrática e que preze pela igualdade e dignidade de todos.

Em relação ao princípio da igualdade, motor das diversas transformações ocorridas nos conteúdos dos direitos, Marramao ${ }^{(16)}$ entende que:

(13) Como observa Aith (AITH, Fernando. Curso de direito sanitário: a proteção do direito à saúde no Brasil. São Paulo: Quartier Latin, 2007), as décadas seguintes à Segunda Guerra Mundial foram de expansão sem precedentes dos serviços de saúde, que se tornaram mais acessíveis com o desenvolvimento do chamado Estado-providência, ou Estado de Bem-Estar Social. A saúde se afirma, então, como "um valor central nas sociedades desenvolvidas" (p. 47).

(14) DALLARI, Sueli Gandolfi; FORTES, Paulo Antônio de Carvalho. Direito sanitário: inovação teórica e novo campo de trabalho. In: SAÚDE e democracia: a luta do CEBES. São Paulo: Ed. Lemos, 1997. p. 195 (15) MARRAMAO, Giacomo. Passado e futuro dos direitos humanos: da "ordem pós-hobbesiana" ao cosmopolitismo da diferença. Texto enviado por ocasião do XVI Congresso Nacional do Conselho Nacional de Pesquisa e Pós-graduação em Direito (Conpedi). Belo Horizonte, 2007. 
a igualdade que se encarna em contextos histórico-culturais efetivos. Mas exatamente em virtude dessa encarnação do princípio de igualdade, assistimos ao surgimento de uma outra polaridade, que não contrasta com a primeira, mas a enriquece e a complica: o princípio da diferença, ou seja, da especificidade cultural como indicador da mudança das circunstâncias e dos contextos socioantropológicos em que se produz a dinâmica dos direitos.

No Brasil, o reconhecimento nacional do direito à saúde, de acordo com os princípios da igualdade e universalidade (que abrangem também a integralidade das ações de saúde), ou a re-territorialização deste direito no Brasil, à luz das disposições contidas nos documentos internacionais, para usar a expressão de Marramao(17), foi uma tarefa complexa.

Tarefa esta que enfrentou as adversidades e raízes do contexto histórico-cultural nacional, em que o cuidado com a saúde inseria-se numa lógica de cidadania regulada, de concepção fragmentada, de prestação de serviços centralizada no nível federal e alicerçada na compra de serviços privados de saúde. Uma lógica que apartava a responsabilidade jurídica do Estado e não conferia aos cidadãos quaisquer recursos jurídicos que lhes permitisse reivindicar saúde. E com destaque para o longo período de ditadura militar que reinou no país, onde qualquer debate público acerca da questão era proibido e reprimido, bem como quaisquer reivindicações coletivas.

O movimento social que ficou conhecido como reforma sanitária ${ }^{(18)}$ teve fundamental importância nesse processo. A reforma vai visar uma reconstrução da própria concepção de saúde, inserindo-a no contexto social brasileiro e uma reconstrução normativa e institucional dos serviços e ações de saúde no país. E, também, um novo olhar sobre o processo saúde-doença, sobre a elaboração e implementação das políticas de saúde, sobre as relações médicas, sobre a formação dos recursos humanos destinados ao trabalho na área da saúde, entre outros, de forma mais próxima e articulada com a concepção de direito humano à saúde, à luz do disposto nos documentos internacionais ${ }^{(19)}$.

(16) MARRAMAO, Giacomo. op.cit., p. 6.

(17) Id. Ibid.

(18) Elias (ELIAS, Paulo. Reforma ou contrarreforma na proteção social à saúde. Lua Nova, São Paulo, n. 40/41, 1997) destaca que a difusão do ideário reformista para a sociedade dá-se principalmente por intermédio do Centro Brasileiro de Estudos em Saúde (CEBES), entidade constituída em 1976 a partir da iniciativa de filiados ao então Partido Comunista Brasileiro (PCB), atingindo assim parte dos profissionais - aqueles mais identificados com a temática sanitária - e, posteriormente, representantes das centrais sindicais (quase exclusivamente profissionais de saúde) e alguns parlamentares (grande parte deles vinculados profissionalmente à saúde).

(19) Dentre os interlocutores da sociedade civil na reforma sanitária, merecem destaque o Centro Brasileiro de Estudos da Saúde - CEBES e Associação Brasileira de Pós-Graduação em Saúde Coletiva - ABRASCO, que se firmaram como importantes atores políticos para o debate da questão e para a divulgação dos estudos e projetos para a reforma. 
Apesar da forte pressão exercida pelos opositores da reforma sanitária, representados pelo setor privado da saúde e suas instituições, bem como pelos membros do governo que se fincavam sobre a tradição privatista do setor da saúde no Brasil, o Presidente da República convocou a VIII Conferência Nacional de Saúde, realizada em março de 1986, sob a responsabilidade do Ministério da Saúde. Este foi, segundo Cohn ${ }^{(20)}$, o evento mais importante para a consolidação das novas propostas para a área da saúde antes da instalação da Assembleia Constituinte de 1988, trazendo as novas propostas abarcadas pela reforma sanitária para o debate público. Como salienta a autora(21), "a questão de fundo que perpassa todo o processo constitui, pois, a compreensão da relação Estado - sociedade na constituição e consolidação de uma ordem democrática", a qual se aproximasse dos princípios de equidade e universalidade dos Estados de bem-estar social, em que pese 0 direito à saúde.

\section{A CONSTITUIÇÃO FEDERAL DE 1988 E O DIREITO À SAÚDE}

A Constituição Federal de 1988 positiva uma nova condição jurídico-formal para o sistema público de saúde brasileiro. Conhecida como Constituição Cidadã porque, segundo Silva(22), "teve ampla participação popular em sua elaboração e especialmente porque se volta decididamente para a plena realização da cidadania", esta Carta Magna eleva a saúde à condição de direito universal integral de todos os cidadãos brasileiros, indistintamente, e também condiciona a sua leitura aos princípios da igualdade e dignidade da pessoa humana, dentre outros previstos em seu bojo.

O art. 6 da Constituição Federal insere a saúde no rol dos direitos sociais tutelados pelo ordenamento jurídico pátrio, e o art. 194 desta Carta Magna reconhece a saúde como parte integrante do sistema de seguridade social do país. Os artigos 196 a 201, por sua vez, instituem uma estrutura política complexa e abrangente para o cuidado com a saúde da população brasileira, com a organização de um Sistema Único de Saúde (SUS) que integra a União, os Estados, os Municípios e o Distrito Federal, formando uma rede regionalizada e hierarquizada, com direção única em cada esfera de Governo e participação da comunidade, destinada a garantir, de forma sistêmica, o direito à saúde de todos os cidadãos.

Ressalta-se que o art. 196 da Constituição Federal diz expressamente que esse direito será garantido "mediante políticas sociais e econômicas que visem à redução do risco de doença e de outros agravos e ao acesso univer-

(20) CONH, Amélia. Os caminhos da reforma sanitária. Lua Nova, São Paulo, n. 19, 1989.

(21) Id. Ibid,, p. 134.

(22) SILVA, José Afonso. Curso de direito constitucional positivo. 16. ed. São Paulo: Malheiros. p. 92 . 
sal e igualitário às ações e serviços para a sua promoção, proteção e recuperação". E que, o art. 198, por sua vez, estabelece as diretrizes do SUS, quais sejam: descentralização, com direção única em cada esfera de governo; atendimento integral, com prioridade para as atividades preventivas, sem prejuízo dos serviços assistenciais e participação da comunidade.

Reconhece-se, pela primeira vez no Brasil, a igualdade, a liberdade e a cidadania como princípios emancipatórios da vida social. E de acordo com Santos ${ }^{(23)}$, neste contexto a desigualdade e a exclusão têm que ser justificadas como exceções, pois o processo societal não mais lhes confere legitimidade. Assim, conclui o autor ${ }^{(24)}$ que "perante elas, a única política social legítima é a que define os meios para minimizar uma e outra"(25).

As diretrizes constitucionais, portanto, balizam a construção da política pública de saúde no Brasil, que por seu arcabouço jurídico sólido, alicerçado na mais alta norma da estrutura escalonada de produção do direito, configura-se como política de Estado, que deve ser observada por todos os governantes, parlamentares e administradores públicos. O direito social à saúde tem raízes jurídicas fortes, capazes de obrigar os governantes à prestação ordenada e sistêmica do mais alto cuidado com a saúde de todos, com respeito às diversidades e à dignidade de cada um, seguindo a diretriz de integralidade de assistência.

O direito à assistência terapêutica e farmacêutica, como parte integrante do direito à saúde, também é instituído em nosso ordenamento jurídico como um direito social. A Lei Orgânica da Saúde - LOS, composta pelas Leis ns. 8.080 e 8.192, ambas de 1990, normatiza amplamente o Sistema Único de Saúde no território nacional, disciplinando as ações e serviços de saúde nos três níveis de governo da federação. Essas leis foram editadas, exatamente, para dar cumprimento aos mandamentos constitucionais relacionados à Saúde.

A LOS estabelece, em seus arts. $6^{\circ}$ e $7^{\circ}$, que dentre as ações que se inserem no campo de atuação do SUS, encontra-se a de "assistência terapêutica integral, inclusive farmacêutica" (art. 6o, I, "d"). Ela deve ser disponibilizada à população com observância ao princípio da integralidade de assistência, entendido como um "conjunto articulado e contínuo das ações e serviços preventivos e curativos, exigidos para cada caso em todos os níveis

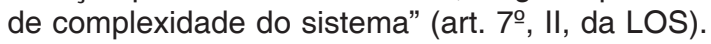

(23) SANTOS, Boaventura de Souza. A gramática do tempo: para uma nova cultura política. São Paulo: Cortez, 2006.

(24) SANTOS, Boaventura de Souza. op. cit., p. 279.

(25) Santos (SANTOS, Boaventura de Souza. op. cit., salienta, ainda, que em relação aos processos de desigualdade e exclusão, a regulação social da modernidade capitalista "estabelece mecanismos que permite controlar ou manter dentro de certos limites esses processos. Mecanismos que, pelo menos, impedem que se caia com demasiada frequência na desigualdade extrema ou na exclusão/ segregação extrema. Estes mecanismos visam uma gestão controlada do sistema de desigualdade/ exclusão" (p. 282). 
Frente a essas disposições legais, Aith $^{(26)}$ salienta que sempre que um cidadão for acometido por uma doença, o Estado brasileiro é obrigado a lhe oferecer atendimento integral, ou seja, todos os recursos médicos, farmacêuticos e terapêuticos que estiverem disponíveis para o tratamento da enfermidade em questão.

Destaca o autor ${ }^{(27)}$ que:

sempre que houver uma pessoa doente, caberá ao Estado fornecer o tratamento terapêutico para a recuperação da saúde dessa pessoa de acordo com as possibilidades oferecidas pelo desenvolvimento científico. Assim, não importa o nível de complexidade exigido, a diretriz de atendimento integral obriga o Estado a fornecer todos os recursos que estiverem ao seu alcance para a recuperação da saúde de uma pessoa, desde o atendimento ambulatorial até os transplantes mais complexos. Todos os procedimentos terapêuticos reconhecidos pela ciência e autorizados pelas autoridades sanitárias competentes devem ser disponibilizados para a proteção da saúde da população.

Todavia, tal tarefa estatal envolve questões complexas a serem enfrentadas. O panorama do mercado de medicamentos e produtos para a saúde no Brasil, e a incorporação tecnológica de inovações terapêuticas, trazem implicações econômicas para a garantia do direito à saúde e, consequentemente, para a formulação de políticas públicas e para a prestação de serviços de saúde que sigam as diretrizes constitucionais e confiram, a todos, o mais alto grau de cuidado com a saúde. Daí a constatação de Faria(28), de que os direitos sociais e a complexidade das questões que envolvem a garantia desses direitos na contemporaneidade, "estão modificando as formas e práticas jurídicas e, com isso, afetando radicalmente a estrutura, a funcionalidade e o alcance do direito positivo".

\section{A GARANTIA EFETIVA DO DIREITO À ASSISTÊNCIA FARMACÊUTICA E A APLICABILIDADE DO PRINCÍPIO DA INTEGRALIDADE DE ASSISTÊNCIA PELO PODER JUDICIÁRIO}

Para a Organização Mundial de Saúde - OMS, a assistência farmacêutica é entendida como um grupo de serviços e atividades relacionados com o medicamento, destinados a apoiar as ações da saúde que demanda a comunidade, os quais devem ser efetivados através da entrega expedita e

(26) AITH, Fernando. Curso de direito sanitário: a proteção do direito à saúde no Brasil. São Paulo: Quartier Latin, 2007.

(27) Id. Ibid., p. 357.

(28) FARIA, José Eduardo. Qual o futuro dos direitos? Estado, mercado e justiça na reestruturação capitalista. São Paulo: Max Limonad, 2002. p. 59. 
oportuna dos medicamentos a pacientes hospitalizados e ambulatoriais, garantidos os critérios de qualidade na farmacoterapia. Para Oliveira, Bermudez e Osório-de-Castro(29), a assistência farmacêutica é considerada parte essencial dos serviços e programas de saúde, a serem implementados e prestados pelo Estado, e representa um processo dinâmico, que abrange o provimento do medicamento em todas as suas etapas constitutivas.

Nessa perspectiva, as políticas públicas de medicamentos são indispensáveis para o exercício do direito social à assistência farmacêutica e terapêutica e devem seguir as diretrizes constitucionais de integralidade e universalidade. Segundo Marques e Dallari(30), "para que o Estado brasileiro possa atender esses preceitos legais, é preciso que implemente políticas públicas e serviços públicos de saúde e assistência farmacêutica, em escala coletiva".

Como as questões que envolvem o acesso aos medicamentos são complexas e vão desde o controle de preços até a criação de Protocolos Clínicos que objetivam racionalizar a prestação coletiva de fármacos, observamos que uma série de medidas, políticas e jurídicas ${ }^{(31)}$, já foram adotadas pelo Estado brasileiro, no que tange à assistência farmacêutica e ao acesso a medicamentos seguros e eficazes. Como destaca Marques ${ }^{(32)}$, como os recursos públicos são limitados frente ao custo de todos os medicamentos disponíveis no mercado ou às inovações terapêuticas, a política pública de medicamentos

não se revela capaz de atender, individualmente, todas as necessidades terapêuticas dos cidadãos brasileiros. Ela é elaborada com base na tomada de decisões coletivas pelo sistema político, sob uma perspectiva coletiva e distributiva. E, dessa forma, adota critérios justificados de inclusão e exclusão de medicamentos dentre os medicamentos ofertados pelo SUS, para possibilitar o atendimento equânime ao maior número de pessoas possível.

(29) OLIVEIRA, Maria Auxiliadora; BERMUDEZ, Jorge; OSÓRIO-DE-CASTRO, Cláudia Garcia. Assistência farmacêutica e acesso a medicamentos. Rio de Janeiro: Fiocruz, 2007.

(30) MARQUES, Silvia Badim; DALLARI, Sueli Gandolfi. A garantia do direito à assistência farmacêutica no Estado de São Paulo. Revista de Saúde Pública, São Paulo, v. 41, n. 2, p. 101-107, 2007, p. 102. (31) Dentre elas podemos citar: a Política Nacional de Medicamentos - PNM, instituída pela Portaria n. 3.916, de 10 de novembro de 1998 do Ministério da Saúde - MS, a adoção da Relação de Medicamentos Essenciais - RENAME, que foi instituída pela Portaria GM/MS n. 507, de 27 de abril de 1999, a Comissão Técnica e Multidisciplinar de Atualização da Relação Nacional de Medicamentos Essenciais - COMARE, instituída pela Portaria GM\MS n. 131/01, os Protocolos Clínicos e Diretrizes Terapêuticas - PCDT, formalizados em diversas portarias, a Lei que estabelece os medicamentos genéricos (Lei n. 9.787, de 10 de fevereiro de 1999), a criação da Câmara de Regulação do Mercado de Medicamentos - CMED, e a ocupação de sua presidência pelo Ministério da Saúde (Lei n. 10.742, de 6 de outubro de 2003 e pelo Decreto n. 4.766, de 26 de junho de 2003), entre outras.

(32) MARQUES, Silvia Badim. A relação do sistema jurídico e do sistema político na garantia do direito social à assistência farmacêutica: o caso do Estado de São Paulo. 2005. Dissertação (Mestrado) - Departamento de Prática de Saúde Pública - Faculdade de Saúde Pública da USP, São Paulo, 2005. p. 8. 
Em que pese todo o esforço empreendido em matéria de assistência farmacêutica pelo Estado brasileiro, estudos ${ }^{(33),(34),(35)}$ demonstram que o número de ações judiciais que demandam medicamentos para o Estado vem crescendo de forma exponencial no Brasil. E que o Poder Judiciário vem condenando o Estado a fornecer os mais diversos tipos de medicamentos, constantes ou não nos Protocolos e Listas oficiais do SUS ${ }^{(36)}$.

Como salienta Marques ${ }^{(37)}$, em pesquisa realizada no Estado de São Paulo, a ideia central mais incidente no discurso dos juízes daquele Estado ao julgarem ações com esta temática, em primeira instância, é a de que "o direito de todos os indivíduos à saúde representa uma consequência indissociável do direito à vida e deve ser garantido integralmente, a despeito de questões políticas, orçamentárias ou entraves burocráticos"(38).

Isso demonstra a importância da aplicação do princípio constitucional da integralidade de assistência pelo Poder Judiciário que, na análise dos casos concretos submetidos a sua apreciação, vem considerando que o cidadão deve ser atendido de forma integral, independentemente do que estipula a política pública concernente à temática, de acordo com a realidade individual posta nos autos. Os juízes vêm respeitando a indicação médica individual para o tratamento de determinada moléstia ou agravo à saúde, a despeito do tratamento que estabelece a política pública.

Tal fato tem sido problematizado pelos gestores públicos de saúde, que acusam o Poder Judiciário de interferir no âmbito de atuação da Administração Pública, desviando os recursos estabelecidos pela política de saúde para o atendimento coletivo, em favor dos seletos cidadãos que acessam

(33) MESSEDER, Ana Maria; OSÓRIO-DE-CASTRO, Cláudia Garcia; LUÍZA, Vera Lúcia. Mandados judiciais como ferramenta para a garantia do acesso a medicamentos no setor público: a experiência do Estado do Rio de Janeiro, Brasil. Cadernos de Saúde Pública, Rio de Janeiro, v. 21, n. 2, p. 525534, 2005.

(34) MARQUES, Silvia Badim; DALLARI, Sueli Gandolfi. op. cit.

(35) VIEIRA, Fabiola Sulpino; ZUCCHI, Paola. Distorções causadas pelas ações judiciais à política de medicamentos no Brasil. Revista de Saúde Pública, São Paulo, v. 41, n. 2, p. 214-222, abr. 2007. (36) De acordo com documento do Conselho Nacional dos Secretários de Saúde (CONASS), 2004, os Protocolos Clínicos e Diretrizes Terapêuticas "objetivam estabelecer claramente os critérios de diagnóstico de cada doença, o tratamento preconizado com os medicamentos disponíveis, as doses corretas, os mecanismos de controle, o acompanhamento e a verificação de resultados, racionalização da prescrição e do fornecimento. Observando ética e tecnicamente a prescrição médica, os PCDT têm, também, o objetivo de criar mecanismos para a garantia da prescrição segura e eficaz" (p. 55). A Relação de Medicamentos Essenciais - RENAME, por sua vez, abrange um elenco de medicamentos necessários ao tratamento e controle das enfermidades prioritárias em saúde pública nos diversos níveis de atenção no País (MS, 2007).

(37) MARQUES, Silvia Badim. op. cit., p. 77.

(38) Nessa pesquisa, 90,3\% das sentenças proferidas pelos juízes da Vara da Fazenda Pública estadual julgam a ação procedente, condenando o Estado de São Paulo a fornecer a medicação pleiteada pelo autor; nenhuma sentença julga o pedido do autor improcedente com o exame do mérito da ação; $9,7 \%$ das sentenças julgam o pedido improcedente por questões processuais, sem a análise do mérito da ação (MARQUES, Silvia Badim. op. cit.). 
a justiça. Vieira e Zucchi(39) expressam este pensamento, chamando-o de "distorções causadas pelas ações judiciais à política de medicamentos no Brasil", em que pese terem analisado apenas ações impetradas contra o Município de São Paulo. Destacam as autoras que 59\% das prescrições eram oriundas de serviços do SUS e $62 \%$ dos medicamentos solicitados eram itens constantes nas políticas de medicamentos (ou seja - é preciso que se note - que não houve impacto na previsão política em $62 \%$ dos casos, mas apenas uma falha na prestação estatal já prevista). Problematizam a questão salientando que $R \$ 876$ mil foram gastos com medicamentos que não fazem parte da Relação Municipal de Medicamentos Essenciais, dos quais $73 \%$, na opinião das autoras, poderiam ser substituídos por outros medicamentos, o que levaria a uma economia nos gastos públicos e a possibilidade de oferta a um número maior de pessoas.

E é o que vem sustentando os entes públicos acionados nessas ações, onde a ideia central presente nos discursos representados pelas suas defesas em juízo, de acordo com Marques $^{(40)}$, ainda em pesquisa realizada no Estado de São Paulo, é a de que "o Estado possui limitações legais e orçamentárias que obstam a garantia da pretensão do Autor". Ou seja, sustentam que o Estado, em suas três esferas de governo, deve fornecer apenas aos cidadãos o que consta nos Protocolos e Listas oficiais do SUS, a despeito das necessidades individuais colocadas nos autos e das indicações terapêuticas individuais (o que consideram, muitas vezes, ser fruto de lobby de indústrias farmacêuticas, muito mais do que reais necessidades terapêuticas). E que atender a pretensão do autor é colocar em risco o atendimento global, de toda a comunidade que não acessa o Poder Judiciário para ver seu direito garantido.

Essa problemática levou o Supremo Tribunal Federal - STF a reconhecer repercussão geral da questão constitucional suscitada em Recurso Extraordinário $^{(41)}$, relativo ao fornecimento de medicamento de alto custo a paciente do Estado do Rio Grande do Norte, às expensas daquele Estado. O STF, neste recurso, questiona se a situação individual pode, sob o ângulo do custo, colocar em risco "a assistência global a tantos quantos dependem de determinado medicamento, de uso costumeiro, para prover a saúde ou minimizar sofrimento decorrente de certa doença". E aponta a necessidade do

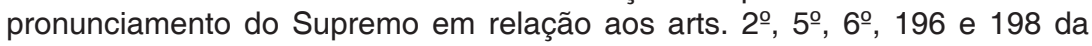
Constituição Federal, "revelando o alcance do texto constitucional".

Percebe-se que essa problemática reflete o atual panorama dos direitos num mundo cada vez mais complexo, onde a garantia efetiva de direitos, como o da saúde, perpassa questões que vão além dos textos normativos e da operação de aplicação positivista da lei.

(39) VIEIRA, Fabiola Sulpino; ZUCCHI, Paola. op. cit.

(40) MARQUES, Silvia Badim. op. cit, p. 61.

(41) Recurso Extraordinário n. 566.471-6, originário do Estado do Rio Grande do Norte. 


\section{DA INDETERMINAÇÃO DO DIREITO E DA NECESSIDADE DA APLICAÇÃO DE PRINCÍPIOS PELO PODER JUDICIÁRIO}

Os limites e contornos do direito à saúde não são claros. Como o exercício deste direito está intrinsecamente relacionado à elaboração de políticas de saúde e à prestação de serviços públicos de saúde, que por sua vez são permeados por questões de ordem social, econômica, e até técnico-científica ${ }^{(42)}$, a prestação jurisdicional tende a inovar nos casos concretos submetidos à sua apreciação. Isto porque pode incidir, de forma reflexa, sobre campos que, habitualmente, não estão dentro dos domínios do sistema jurídico.

Como destaca Faria(43), o Judiciário vem sendo acusado de "destecnificar" a aplicação da lei e por consequência acarretar a "judicialização" da vida administrativa e econômica. Em suas próprias palavras ${ }^{(44)}$,

como a magistratura não pode deixar sem resposta os casos que Ihes são submetidos, independentemente de sua complexidade técnica, e de suas implicações políticas, econômicas e sociais, ela se sente impelida a exercer uma criatividade decisória que acaba transcendendo os limites da própria ordem legal. Afinal, nos casos difíceis, nos quais a interpretação a ser dada a uma norma, lei ou código não está clara ou é controvertida, os juízes não têm outra opção a não ser inovar, usando o próprio julgamento político.

Ora, em matéria de assistência farmacêutica e terapêutica, a análise dos casos concretos submetidos à apreciação dos juízes tem alicerce jurídico em garantias constitucionais claras, e fincadas em princípios, como o de universalidade e integralidade de assistência à saúde. Princípios amplos, cuja indeterminação conceitual e de seu alcance tendem a levar os juízes a um julgamento para além da simples leitura da lei e dos elementos normativos. A própria leitura dos princípios, em face da complexidade de cada caso concreto, tende a levar o aplicador da lei a uma interpretação eivada de fatores políticos e até morais. Isso abala a ilusória certeza e segurança jurídicas sobre as quais estrutura-se a teoria do direito na modernidade.

(42) FARIA, José Eduardo. Qual o futuro dos direitos? Estado, mercado e justiça na reestruturação capitalista. São Paulo: Max Limonad, 2002, ressalta que, em relação à disciplina jurídica de matérias complexas como a biomedicina, a biotecnologia e a biociência, "os poderes Executivo e Legislativo cada vez mais procuram dividir ou partilhar essa responsabilidade, por meio de sistemas de consultas públicas, painéis de discussão, entendimento com setores sociais interessados, colaboração com comunidades profissionais estruturadas, assessoria de centros de pesquisa, diálogo com instituições universitárias de elite e pedidos de relatórios técnicos e pareceres a cientistas, peritos e especialistas das mais diferentes áreas do conhecimento " (p. 89).

(43) FARIA, José Eduardo. O sistema brasileiro de justiça: experiência recente e futuros desafios. Estudos Avançados, São Paulo, v. 18, n. 51, p. 103-125, 2004.

(44) Id. Ibid., p. 106. 
Teoria esta que se ergue sobre os fundamentos da racionalidade, típicos da ciência moderna, que pregam o purismo metodológico e a construção lógica do ordenamento jurídico, com base apenas neste próprio ordenamento. As teorias positivistas do direito afastam, do direito e da ciência jurídica, quaisquer elementos que não os normativos, decorrentes do arcabouço de leis e normas que regem o Estado. Voltam-se, portanto, para a apreensão do direito como norma jurídica, como conteúdo de uma norma jurídica ou como determinado por meio de uma forma jurídica, independentemente do contexto histórico-social de produção desses direitos. E, não havendo direito senão o direito estatal, emanado do Estado, a metodologia jurídica funda-se sobre paradigmas lógico-dedutivos, ou seja, sobre a dedução lógica das normas postas validamente pelo Estado.

A ciência, e especificamente a ciência jurídica, procura então, à luz dos ensinamentos de Kelsen ${ }^{(45)}$, traduzir o direito em um método de aplicação racional, que por si só é capaz de eliminar os conflitos decorrentes da aplicação da lei. Ou seja, mediante a utilização de um método lógico, puro, a ciência jurídica seria capaz de revelar o alcance das leis e assim balizar a interpretação de seus operadores, conferindo segurança e certeza as suas operações.

Como salienta Menelick de Carvalho $\mathrm{Neto}^{(46)}$, em relação à racionalidade da ciência moderna:

Tem-se um discurso científico quando sejam perfeitamente dadas as regras de sua formação e as de sua transformação, mediante a definição dos termos usados nas proposições iniciais e o perfeito conhecimento das regras para o desenvolvimento analítico do discurso e sua aplicação na prática.

As equações decorrentes das operações jurídicas, desta forma, são resolvidas dentro do arcabouço jurídico, não necessitando de outros elementos que prejudiquem a sua autonomia e pureza metodológica, por meio de um método preestabelecido, capaz de revelar o sentido e os limites das normas jurídicas e assim solucionar os problemas relativos à sua aplicação. Todavia, como adverte Faria(47), o rigor lógico-formal imposto pelo normativismo positivista às técnicas interpretativas de caráter exegético jamais é suficientemente amplo para eximir o aplicador da lei de um poder criativo. A ilusão, ou o delírio iluminista, consistiu em acreditar que um método, puro e lógico, seria capaz de solucionar todos os problemas decorrentes da aplicação da lei e dos textos normativos ${ }^{(48)}$.

(45) KELSEN, Hans. Teoria pura do direito. 6. ed. São Paulo: Martins Fontes, 1998.

(46) CARVALHO NETTO, Menelick. A sanção no procedimento legislativo. Ano do centenário da Faculdade de Direito da UFMG. Belo Horizonte, 1992. p. 217.

(47) FARIA, José Eduardo. O Judiciário e os direitos humanos e sociais: notas para uma avaliação da justiça brasileira. In: (Org). Direitos humanos, direitos sociais e justiça. 3. tir. São Paulo: Malheiros 2002. p. 94-112.

(48) O próprio Kelsen (KELSEN, Hans. Teoria pura do direito. 6. ed. São Paulo: Martins Fontes, 1998), no último capítulo da sua teoria pura do direito, revisto após a primeira edição da obra, 
Rodrigues ${ }^{(49)}$ salienta que:

As teorias positivistas buscam estabilizar expectativas sem recorrer a tradições éticas como suporte para a legitimidade das normas jurídicas. Kelsen e Hart buscaram conceber o ordenamento jurídico como sistema fechado de regras cuja compreensão seja independente da política e da moral. Reduz-se o Direito a uma determinada história institucional, com abstração de qualquer princípio suprapositivo.

Salienta ainda o autor que a identificação entre racionalidade e neutralidade pretendida pela Teoria Pura revela uma concepção de ciência centrada no sujeito, incapaz de discernir os limites e possibilidades da razão prática em sociedades pós-convencionais de crescente complexidade. Direitos como o da saúde são indeterminados por sua própria natureza, norteada por princípios jurídicos amplos e conduzida por atuações políticas (políticas públicas) que acabam por tangenciar fatores econômicos, tecnológicos, sociais e culturais, relacionados com a prestação de cuidados de saúde, e com as mais variadas necessidades de saúde da população.

A crença iluminista de que bons textos normativos e bons textos científicos seriam capazes de eliminar os desafios da aplicação da lei e determinar a interpretação subjetiva de cada operador do direito, começa a ser colocada em cheque. A evidência de que qualquer texto é passível de múltiplas interpretações, por mais fechada que procure ser sua linguagem, fica mais patente com a positivação dos princípios constitucionais e de uma ordem jurídica focada em princípios, à luz da concepção de direitos humanos, e de efetiva igualdade e dignidade humana. $E$ também evidencia que, no limite da interpretação, outros elementos que não os estritamente normativos permeiam as decisões e aplicação desses direitos.

Neste contexto, merece destaque a teoria de Ronald Dworkin que, segundo Rodrigues ${ }^{(50)}$ :

Face à crença irracional de que textos racionalmente elaborados poderiam reduzir a complexidade da tarefa interpretativa e ao ceticismo decisionista, buscou resgatar a crença na força normativa dos direitos virando do avesso a pureza epistemológica pretendida pelo positivismo e restaurando a plausibilidade do conceito de justiça em termos pós-metafísicos e pós-convencionais.

reconhece o problema: e se a autoridade não se deixar limitar pela lei, e pelas interpretações a ela fornecidas pela ciência do direito? E se o aplicador não tomar como base a ciência jurídica para eleger uma das interpretações possíveis de uma norma?

(49) RODRIGUES, Guilherme Scotti. A afirmação da justiça como a tese da única decisão correta: o enfrentamento da questão do caráter estruturalmente indeterminado do direito moderno. 2008. Dissertação (Mestrado) — Faculdade de Direito. Universidade de Brasília, 2008. p. 15.

(50) Id. Ibid., p. 11. 
Neste sentido, Dworkin defende a importância de se "levar os direitos a sério" e que, para isso, o aplicador deve considerar as especificidades de cada caso concreto submetido a sua apreciação e, assim, buscar uma única resposta correta no ordenamento jurídico em sua integridade. Não se trata de sacrificar direitos ou escolher entre valores concorrentes (que não se confundem com interesses), mas sim, de compreender os princípios como normas deontológicas que estabelecem direitos e deveres e que preexistem no momento da decisão e que irão levar o aplicador, diante do reconhecimento das peculiaridades e necessidades do caso concreto, a uma única resposta correta, a uma interpretação e aplicação corretas da lei e das normas constitucionais. Uma leitura harmônica dos princípios e das regras e textos normativos, que será única para cada caso concreto posto em juízo.

Dworkin(51) propõe um modelo focado em direitos e não apenas no texto jurídico, onde admite a existência de direitos morais (focados em princípios) que, em última instância, norteiam o aplicador da lei. Sem prescindir do texto jurídico, e de sua importância, o autor sustenta, todavia, que ele não é a única fonte de direitos. Um juiz que segue a concepção de Estado de Direito focada em direitos tentará, num caso controverso, estruturar algum princípio que, para ele, capte, no nível adequado de abstração, os direitos morais das partes que são pertinentes às questões levantadas pelo caso. $\mathrm{E}$ ressalta que ele não pode aplicá-lo a menos que este, como princípio, seja compatível com a legislação, ou seja, o princípio não pode se deslocar das normas e dos textos normativos. Em suas palavras, "o princípio não deve estar em conflito com outros princípios que devem ser pressupostos para justificar a regra que está aplicando ou com qualquer parte considerável das outras regras"(52).

Os direitos fundamentais da pessoa humana tangenciam concepções de princípios morais e éticos, que traduzidos em linguagem e roupagem jurídicas permitem que o aplicador da lei, sem prescindir dos textos legais, os utilize com primazia na solução de casos controversos. E que levem em consideração as peculiaridades dos diversos grupos e pessoas que acessam o Poder Judiciário ou que reivindicam direitos junto a outros órgãos públicos, com necessidades específicas, buscando respeito as suas diversidades e diferenças que, muitas vezes, não podem ser contempladas pela letra fria da lei.

Como destaca Rodrigues ${ }^{(53)}$ a leitura positivista do direito como sistema autossuficiente de regras, que pretendem regular com alto grau de determinação suas situações de aplicação, deixa escapar a dimensão central de qualquer ordenamento jurídico pós-convencional: "sua estrutura princi-

(51) DWORKIN, Ronald. Uma questão de princípio. São Paulo: Martins Fontes, 2001.

(52) Id. Ibid., p. 15.

(53) RODRIGUES, Guilherme Scotti. op. cit., p. 21. 
piológica, necessariamente indeterminada em abstrato, embora determinável em concreto, aberta hermeneuticamente à construção intersubjetiva dos sentidos".

A aplicação do princípio da integralidade de assistência à saúde, nos casos concretos submetidos ao Poder Judiciário, evidencia o choque deste paradigma, pois, permite que o juiz inove em cada caso concreto e garanta aos cidadãos os mais diversos medicamentos solicitados para o tratamento de suas moléstias. Destaca-se ainda com base na pesquisa efetuada por Marques $^{(54)}$, que os cidadãos solicitam medicamentos não com base nos seus julgamentos pessoais sobre o melhor tratamento de saúde e sim com base numa prescrição médica, emanada por médico que pode ou não compor a rede do SUS.

Os princípios constitucionais, portanto, aplicados de acordo com as Leis que regem a temática, bem como com os demais textos normativos, podem levar os juízes a respeitar as mais diversas particularidades e a garantir cuidado dos problemas de saúde dos quais padecem os cidadãos brasileiros e, com isso, a história de uma cidadania regulada, onde a saúde não era um direito de todos e as pessoas que sofriam dos mais diversos males podiam ser deixadas à própria sorte, sem tratamento e sem medicamento adequado, parece ficar para trás.

Sem pesar a importância da padronização coletiva de medicamentos, tratamentos e insumos de saúde, através de políticas públicas, os princípios constitucionais permitem, e devem permitir, que o juiz garanta, face às peculiaridades e indicações médicas de cada caso concreto, outros medicamentos e tratamentos que podem representar, muitas vezes, a garantia de uma vida digna ou minimizar o sofrimento e a dor de alguém.

\section{O PROJETO DE LEI N. 219/2007 DO SENADO FEDERAL}

$\mathrm{Na}$ contramão das teorias contemporâneas do direito que reconhecem a força irradiadora dos princípios jurídicos e constatam a falência do modelo positivista e da possibilidade da linguagem solucionar os problemas oriundos da aplicação da lei, tramita no Senado Federal o Projeto de Lei de n. 219 de 2007, que pretende estabelecer um conceito de integralidade de assistência à saúde.

Pretende o referido Projeto de Lei alterar o art. 6으 da Lei n. 8.080/90, para introduzir o seguinte conceito de integralidade, sob a justificativa de

(54) MARQUES, Silvia Badim. op. cit. 
solucionar o conflito relacionado com a garantia do direito social à assistência farmacêutica pelo Poder Judiciário e com o lobby das indústrias farmacêuticas dentro do SUS ${ }^{(55)}$ :

A integralidade da assistência terapêutica, inclusive farmacêutica, de que trata a alínea d do inciso I do art. 6ำ consiste em:

I - oferta de procedimentos terapêuticos ambulatoriais e hospitalares constantes de tabelas elaboradas pelo gestor federal do SUS, realizados no território nacional em serviço próprio, conveniado ou contratado;

II - dispensação de medicamento prescrito em serviço próprio, conveniado ou contratado, cuja prescrição esteja em conformidade com as diretrizes terapêuticas instituídas pelo gestor federal do SUS em protocolo clínico para o agravo à saúde a ser tratado.

$\S 1^{\circ} \mathrm{Na}$ falta do protocolo a que se refere o inciso II do caput, a dispensação limitar-se-á aos produtos constantes de relações de medicamentos essenciais e de medicamentos de dispensação excepcional elaboradas pelo gestor federal do SUS.

Ao reduzir o princípio constitucional de integralidade de assistência à saúde à oferta pública dos medicamentos, selecionados pelo gestor público, o presente projeto de lei representa um retrocesso em relação à garantia ampla dos direitos humanos, focada em princípios que permitem a garantia digna da saúde de todos. Salienta-se que muitos problemas perpassam as políticas públicas de medicamentos, desde a alegada falta de verbas, até o atraso na revisão da lista de medicamentos essenciais - RENAME. Apesar de serem elaborados com base na medicina baseada em evidências, os Protocolos ${ }^{(56)}$ e Listas oficiais não contemplam todas as necessidades de saúde da população, bem como podem apresentar falhas e demoras em sua atualização, de acordo com novas tecnologias e recursos disponíveis.

(55) Trecho da justificativa do Projeto de Lei em tela: "Amparados por esses preceitos constitucionais e legais, os tribunais brasileiros expediram, nos últimos anos, várias decisões liminares que obrigaram os gestores do SUS a fornecer medicamentos não ofertados ou não disponíveis nas farmácias das unidades públicas de saúde, sob pena de prisão do gestor e multa, em caso de descumprimento. Algumas das decisões obrigaram o fornecimento até mesmo de medicamentos ainda não registrados no País. A maioria dessas liminares tem como objetivo atender à prescrição de produtos de alto custo, muitos deles recém-lançados em outros países e ainda não disponíveis no Brasil. O lobby da indústria e do comércio de produtos farmacêuticos junto a associações de portadores de certas doenças e o intenso trabalho de marketing junto aos médicos fazem com que tanto os usuários quanto os prescritores passem a considerar imprescindível o uso de medicamentos novos. Em regra esses produtos são de altíssimo custo, como já mencionado, mas nem sempre são mais eficazes que outros de custo inferior, indicados para a mesma doença".

(56) Os Protocolos Clínicos e Diretrizes Terapêuticas (PCDT) buscam padronizar a prestação coletiva de fármacos, de acordo com a melhor evidência técnico-científica de eficácia, levando em consideração tanto os aspectos farmacológicos, quanto a relação custo/efetividade desse bens, para que possam ser distribuídos à população, sob a perspectiva de seu uso racional e seguro. 
Se por um lado o Poder Judiciário pode, e deve, conhecer melhor a política pública de medicamentos e buscar proferir decisões de forma harmônica com a prestação coletiva de fármacos, por outro lado, a ameaça de restringir a aplicação de um princípio constitucional à política pública estabelecida pode representar um retrocesso em relação à garantia do direito à saúde, nos moldes em que foi concebido pela Constituição Federal de 1988 e pela tão sonhada reforma sanitária no Brasil.

Negar a força do princípio de integralidade de assistência à saúde e amarrá-lo à política pública é deixar o cidadão à mercê dos administradores públicos. Apesar dos gestores de saúde merecerem todo o respeito e consideração em sua escolha discricionária de oferta coletiva de fármacos, o direito deve ir além, pois os administradores, e gestores públicos podem negligenciar o atendimento individual e deixar os cidadãos sem atendimento específico, que seja capaz de, na prática, salvar sua vida ou minimizar seu sofrimento. E um ordenamento jurídico que preze pela dignidade da vida humana e pela universalidade e integralidade de ações de saúde, deve salvaguardar o direito dessas pessoas reivindicarem suas necessidades, e de serem atendidas pelo Estado.

Ademais, uma norma geral e abstrata não será capaz de resolver o problema da aplicação da lei, nem de condicionar a interpretação de um princípio constitucional, como já demonstram as teorias contemporâneas do direito $^{(57)}$. As normas gerais e abstratas apenas iniciam o problema do direito e são o ponto de partida para eventuais pretensões abusivas, como o lobby indevido de indústrias farmacêuticas. Não é a partir do estabelecimento de normas gerais e abstratas que condutas são coibidas, mas sim, a partir delas, condutas contrárias ao direito posto podem ser exercidas e contrapostas a pretensões legítimas.

Outras medidas, políticas, podem ser utilizadas com muito mais sucesso para coibir as pretensões abusivas das indústrias farmacêuticas, como o controle de preços de medicamentos ${ }^{(58)}$, a regulamentação da propaganda de medicamentos ${ }^{(59)}$ entre outros.

(57) RODRIGUES, Guilherme Scotti. op. cit.

(58) Por exemplo: Lei n. 9787 de 10 de fevereiro de 1999, que estabelece os medicamentos genéricos; ou Lei n. 10.742 de 6 de outubro de 2003 e Decreto n. 4.766 de 26 de junho de 2003, que criaram a Câmara de Regulação do Mercado de Medicamentos - CMED e designaram como seu presidente o Ministério da Saúde.

(59) Dentre outros documentos legais que disciplinam a regulamentação da propaganda de medicamentos, a Resolução n. 102 da ANVISA - Agência Nacional de Vigilância Sanitária, de 30.11 .2000 , representa o principal documento, hoje vigente, para nortear a regulação estatal neste âmbito, e restringir, assim, a veiculação dessas propagandas. Essa resolução aprova o regulamento sobre propagandas, mensagens publicitárias e promocionais e outras práticas cujo objeto seja a divulgação, promoção e comercialização de medicamentos, nacionais ou importados. 
A interpretação concreta de princípios constitucionais, como o da integralidade de assistência à saúde e dignidade da pessoa humana, pode ultrapassar esta norma geral e abstrata que se pretende aprovar no Senado Federal. Diante de um caso concreto em que um cidadão se encontre acometido por uma moléstia cujo tratamento, individualmente dispensado, não se encontre nos Protocolos e Listas oficiais, o juiz, ou o administrador público, poderia negar-se a fornecer tal tratamento, apenas com base nesta possível Lei? Ou ainda, no caso de não existir qualquer tratamento padronizado para uma doença ou agravo à saúde, poderia o juiz negar atendimento ao cidadão, com base no projeto de Lei sob análise? Pensar no coletivo seria deixar de atender necessidades individuais de saúde, que não se encontram padronizadas?

À luz dos ensinamentos de Dworkin, a solução correta para cada caso, mesmo com a aprovação da pretensa Lei, numa concepção de direitos e não de textos normativos, poderia continuar a se focar nos princípios ora elencados e na sua leitura harmônica com as demais normas, que revelariam assim o que vem a ser integralidade em cada situação concreta.

Marramao ${ }^{(60)}$ adverte que devemos entender a dimensão do universalismo jurídico não como um modelo estático e pré-constituído, mas como um fazer-se histórico dinâmico. " $E$, consequentemente, colher na Declaração Universal de 1948 uma aquisição evolutiva a ser ancorada não tanto no plano meta-histórico do Direito natural, mas, ao contrário, na cláusula histórica do "nunca mais'." E o "nunca mais", aqui, seria a falta de amparo legal ao cidadão, que o impossibilite de reivindicar seu direito à saúde, com igual respeito e consideração as suas necessidades e diferenças.

\section{CONSIDERAÇÕES FINAIS}

Ressalta-se a importância de se observar cada caso concreto submetido ao Poder Judiciário ou ao Poder Executivo, para que, no universo particular dessas situações específicas, possam ser aprofundados os questionamentos e assim, para cada um, estabelecer-se o que vem a ser integralidade de assistência à saúde, bem como levantar-se outras possibilidades de tratamento aos doentes, com igual respeito e consideração àqueles cujas necessidades de saúde não se enquadram em protocolos, ou que a urgência do tratamento requer uma intervenção rápida, ou ainda, àqueles que possuem particularidades que devem ser observadas.

Em que pese a importância de se padronizar, mediante políticas públicas, tratamentos uniformes para serem ofertados publicamente, racionalizando

(60) MARRAMAO, Giacomo. op. cit., p. 7. 
os recursos à disposição do Estado, não podemos nos desviar da necessária amplitude do princípio da integralidade. Princípio este que, constitucionalmente garantido, nos permite vislumbrar em cada caso concreto, único e particular, levado à apreciação do gestor público ou do Poder Judiciário, o que vem a ser integralidade de assistência à saúde, capaz de conferir, nas particularidades e diferenças, saúde e dignidade a cada um.

O fazer-se histórico do direito à saúde no Brasil precisa enfrentar a problemática ora exposta, mas sem, contudo, retroceder aos princípios contidos na Declaração Universal e acolhidos pela Constituição Federal de 1988.

\section{REFERÊNCIAS BIBLIOGRÁFICAS}

AITH, Fernando. Curso de direito sanitário: a proteção do direito à saúde no Brasil. São Paulo: Quartier Latin, 2007.

CARVALHO NETTO, Menelick. A sanção no procedimento legislativo. Ano do centenário da Faculdade de Direito da UFMG. Belo Horizonte, 1992.

COHN, Amélia; ELIAS, Paulo. Saúde no Brasil: políticas e organização de serviços. 5. ed. São Paulo: Cortez, 2003.

CONASS. Conselho Nacional dos Secretários de Saúde. Sistema Único de Saúde. Para entender a gestão do SUS. Brasília: CONASS, 2007. (Coleção PROGESTORES. Livro 1).

CONH, Amélia. Os caminhos da reforma sanitária. Lua Nova, São Paulo, n. 19, 1989. 2002.

et. al. A saúde como direito e como serviço. 3. ed. São Paulo: Cortez,

COSTA, Ediná Alves; ROZENFELD, Sueli. Constituição da vigilância sanitária no Brasil. In: ROZENFELD, S. (Org.). Fundamentos da vigilância sanitária. Rio de Janeiro: Fiocruz, 2001.

DALLARI, Sueli Gandolfi. Os Estados brasileiros e o direito à saúde. São Paulo: Hucitec, 1995.

; FORTES, Paulo Antônio de Carvalho. Direito sanitário: inovação teórica e novo campo de trabalho. In: SAÚDE e democracia: a luta do CEBES. São Paulo: Ed. Lemos, 1997.

DWORKIN, Ronald. Uma questão de princípio. São Paulo: Martins Fontes, 2001.

ELIAS, Paulo. Reforma ou contra-reforma na proteção social à saúde. Lua Nova, São Paulo, n. 40/41, 1997. 
FARIA, José Eduardo. O Judiciário e os direitos humanos e sociais: notas para uma avaliação da justiça brasileira. In: (Org.). Direitos humanos, direitos sociais e justiça. 3. tir. São Paulo: Malheiros, 2002. p. 94-112.

O sistema brasileiro de justiça: experiência recente e futuros desafios. Estudos Avançados, São Paulo, v. 18, n. 51, p. 103-125, 2004.

Qual o futuro dos direitos? Estado, mercado e justiça na reestruturação capitalista. São Paulo: Max Limonad, 2002.

KELSEN, Hans. Teoria pura do direito. 6. ed. São Paulo: Martins Fontes, 1998. MARQUES, Silvia Badim. A relação do sistema jurídico e do sistema político na garantia do direito social à assistência farmacêutica: o caso do Estado de São Paulo. 2005. Dissertação (Mestrado) - Departamento de Prática de Saúde Pública - Faculdade de Saúde Pública da USP, São Paulo, 2005.

; DALLARI, Sueli Gandolfi. A garantia do direito à assistência farmacêutica no Estado de São Paulo. Revista de Saúde Pública, São Paulo, v. 41, n. 2, p. 101-107, 2007.

MARRAMAO, Giacomo. Passado e futuro dos direitos humanos: da "ordem pós-hobbesiana" ao cosmopolitismo da diferença. Texto enviado por ocasião do XVI Congresso Nacional do Conselho Nacional de Pesquisa e Pósgraduação em Direito (Conpedi). Belo Horizonte, 2007.

MESSEDER, Ana Maria; OSÓRIO-DE-CASTRO, Cláudia Garcia; LUÍZA, Vera Lúcia. Mandados judiciais como ferramenta para a garantia do acesso a medicamentos no setor público: a experiência do Estado do Rio de Janeiro, Brasil. Cadernos de Saúde Pública, Rio de Janeiro, v. 21, n. 2, p. 525-534, 2005.

OLIVEIRA, Maria Auxiliadora; BERMUDEZ, Jorge; OSÓRIO-DE-CASTRO, Cláudia Garcia. Assistência farmacêutica e acesso a medicamentos. Rio de Janeiro: Fiocruz, 2007.

RODRIGUES, Guilherme Scotti. A afirmação da justiça como a tese da única decisão correta: o enfrentamento da questão do caráter estruturalmente indeterminado do direito moderno. 2008. Dissertação (Mestrado) — Faculdade de Direito. Universidade de Brasília, 2008.

SANTOS, Boaventura de Souza. A gramática do tempo: para uma nova cultura política. São Paulo: Cortez, 2006.

SANTOS, Wanderley Guilherme. Cidadania e justiça: a política social na ordem brasileira. Rio de Janeiro: Campus, 1979.

SILVA, José Afonso. Curso de direito constitucional positivo. 16. ed. São Paulo: Malheiros. 1999.

VEYNE, Paul. Como se escreve a história. 4. ed. Brasília: Ed. da UnB, 1988.

VIEIRA, Fabiola Sulpino, ZUCCHI, Paola. Distorções causadas pelas ações judiciais à política de medicamentos no Brasil. Revista de Saúde Pública, São Paulo, v. 41, n. 2, p. 214-222, abr. 2007. 